\title{
Profiling E-business Practices amongst Small and Medium-Sized Enterprises Using a Fit Perspective
}

\author{
Rosli Mohamad ${ }^{1}$ and Noor Azizi Ismail ${ }^{2}$ \\ ${ }^{1}$ College of Business, Universiti Utara Malaysia, Kedah, Malaysia \\ ${ }^{2}$ Othman Yeop Abdullah Graduate School of Business, Universiti Utara Malaysia, Kedah, Malaysia
}

\begin{abstract}
E-business as a multifaceted application has vast capabilities to support today's business. Nevertheless, these capabilities do not equally benefit all firms. Therefore, appropriate selection of e-business solutions would substantially enhance firm efficiency and effectiveness. Despite extensive research in this domain, there are limited works that explore the extent to which SMEs successfully align diverse e-business capabilities to their strategic business functions. This is crucial considering that SMEs have relatively limited resources and thus make them more selective in ebusiness-related investments. This study therefore explores the current state of e-business fit (alignment) among Malaysian SMEs. The next attempt is to reveal any possible patterns that represent firms with respect to their e-business alignment characteristics. A self-administered survey was conducted on 140 SMEs owner/manager in order to investigate present status of ebusiness alignment across various business processes. The results generally indicate that firms perceive a relatively higher level of alignment in terms of information searching, sales, and internalrelated functions relative to other functions. A cluster analysis further classifies firms into three (3) groups with somewhat distinct alignment patterns. Despite several limitations, this study has provided insights on how e-business penetrates across firm operation and the extent to which it corresponds to the most salient functions of the business. This study, therefore, supports the claim that SMEs have different priorities over e-business solutions in support of various business functions. These findings have also provided more insights such as why some firms do not progress into a higher e-business ladder.
\end{abstract}

Keywords: e-business, alignment, SMEs, Malaysia

\section{Introduction}

Small and Medium-sized Enterprises (SMEs) anchor economic growth of most developing nations considering their substantial contribution to gross domestic product (GDP) and employment opportunities. Consequently, the government through several agencies has been considering various efforts to enhance firms efficiency and productivity. As such, deployment of Information Technology/Information Systems (IT/IS) becomes one of the catalysts for such efforts.

Internet commercialization further spurs greater interest towards IT/IS usage among firms. Internet features such as global connectivity and public networking system offer wide range of online-based applications

Copyright (C) 2011 Rosli Mohamad and Noor Azizi Ismail. This is an open access article distributed under the Creative Commons Attribution License unported 3.0, which permits unrestricted use, distribution, and reproduction in any medium, provided that original work is properly cited. Contact author: Rosli Mohamad. E-mail: roslim@uum.edu.my 
(e-business) as a means to transform various aspects of business. Specifically, these applications benefit firms in terms of making global presence, improving business process efficiency, and widening market share. Due to varying definitions, this paper particularly refers to e-business as "a transformation of key business processes by using an Internet technology" (Meckel et al, 2004). Therefore, the words e-business and Internet are used interchangeably throughout this paper.

E-business offers vast capabilities to support business ranging from information searching, communication and transactional-related tasks (Wilson et al, 2008). Nonetheless, these capabilities do not equally benefit all firms (Roberts \& Toleman, 2007). Specifically, due to resources constraint, SMEs are getting more selective on e-business related investment. Thus, their e-business deployment could have been restricted to certain aspects of firm operation. Most importantly, e-business turns to be worthwhile if its deployment corresponds highly to the most crucial aspects of firm operation (Bharati \& Chaudhury, 2006). This clearly indicates the importance of aligning multifaceted e-business capabilities across various firm operations. Having e-business capabilities aligned with the most crucial business functions would then optimize its values to the firm (Raymond \& Bergeron, 2008).

The issue of IT/IS alignment (fit) has received considerable attention among researchers (Chan \& Reich, 2007). Nevertheless, there are limited attempts to explore IT/IS alignment amongst SMEs (Silvius et al, 2009). Additionally, earlier works mainly concentrate on IT/IS alignment in general, (Cragg et al, 2002) or alignment of specific business function (Ismail \& King, 2007; Hooper et al, 2010). Works are still limited in investigating the alignment on specific IT/IS, such as Internet-based solutions (Raymond \& Bergeron, 2008). Hence, this study has two major objectives;

i. to assess systematically the current state of e-business alignment among SMEs; ii. to distinguish firms into several meaningful categories based on their ebusiness alignment characteristics.

This paper contributes to the existing literature in several aspects. First, it investigates alignment issue from a specific type of IT/IS application. Internet as compared to other types of IT/IS is unique, as it is an open standard system that enables global connectivity and it uses public network as a backbone infrastructure (Zhu \& Kraemer, 2005). Furthermore, Internet technology has both computing and communicating capabilities (Premkumar, 2003). Such unique capabilities promote efficiency for inter-firm interaction, transactions processing and market expansion initiative. Secondly, instead of investigating IT/IS alignment from strategic perspective (Cragg et al, 2002; Chan et al, 2006), this study evaluates e-business alignment at business process level. As Melville and Ramirez (2008) emphasize, different business processes have relatively inconsistent degree of complexity, therefore require different kinds of Internet support. Additionally, examining e-business alignment at process level would facilitate firms to locate highly supported or least supported business operation (Cragg et al, 2007).

In order to achieve these objectives, the following section proceeds by exploring development of IT/IS and e-business from SMEs perspective and analyzing earlier works on IT/IS alignment. Based upon the review, the research model for this paper is then presented at the end of the section.

\section{Conceptual Framework}

\section{IT, E-business, and SMES}

SMEs are comparatively different from their larger counterparts in several aspects. They have the least complicated structure, which make them easily adaptable to environmental changes (Raymond et al, 2005). In turn, the decision making process 
becomes more centralized (Bharati \& Chaudhury, 2006). With respect to risk, SMEs are encountering greater business risk than larger firms apart from facing higher rate of business failure (DeLone, 1988). Due to limited access to information, SMEs also have to deal with greater business uncertainty in managing daily operation of the firms (Aragon-Correa \& Cordon-Pozo, 2005).

Size has been identified as one of the possible factors that influence firms use of IT/IS. Generally, larger firms have greater capabilities to embrace IT/IS as compared to SMEs (Bharati \& Chaudhury, 2006). This is particularly due to several factors. First, SMEs usually have no clear strategy to facilitate effective IT/IS usage (Cragg \& Zinatelli, 1995). Secondly, smaller firms have limited financial resources and competent employees to initiate or to manage firms' IT/IS applications (Thong, 2001). Lack of internal IT experts subsequently puts more pressure on firms to rely upon external IT experts to facilitate IT/IS related projects (Premkumar, 2003). Thirdly, SMEs mainly embrace IT/IS to support operational functions without any strategic focus (Schubert \& Leimstoll, 2007). Thus, they tend to adopt lower-end applications that are inadequate to firms (Thong et al, 1996). Such practice obviously restricts firms from fully optimizing the real value from IT/IS deployment.

Since Internet booming, more efforts have been initiated to investigate the Internet impacts on the SMEs. This transformation deserves further investigation as the Internet technology has different impacts on SMEs than other types of IT/IS applications. Considering these differing characteristics, a unique model is therefore needed to understand the roles of specific IT/IS innovation in SMEs (Levy \& Powell, 2000). Based on the above argument, it is essential to investigate the use of e-business application among SMEs.

Large portions of studies have tried to establish wide range of drivers/barriers of e- business practices (Mohamad \& Ismail, 2009; Parker \& Castleman, 2007). There are also growing attempts to investigate e-business diffusion across business functions (Bharati \& Chaudhury, 2006; Alam et al, 2007) and the impacts of e-business on firm performance (Pflugheoft et al, 2003; Raymond \& Bergeron, 2008).

Internet-based applications have been gradually diffused into many aspects of firm value chains (Porter, 2001). These value chains, comprising of physical components and information processing components, demand for different degree of Internet technology support (Bharati \& Chaudhury, 2006). Several works have clearly indicated that the Internet does have different roles in supporting various firm functions. For example, Magal and Kosalge (2006) report that marketing, procurement, in-bound and out-bound functions are to receive relatively higher Internet support than other functions. Meanwhile, firms in production sector heavily consider e-business to be used for primary functions while service sectors perceive greater e-business capabilities in support/secondary functions.

Despite vast e-business potentials, not all firms perceive e-business as a strategic solution to them (Bharadwaj \& Soni, 2007). Thus, it is not reasonable to assume that all firms would extensively deploy the Internet to support all aspects of their business. In such situation, firms may consider applications that provide substantial impact on their business operation or applications that are aligned with firm's objectives (Levy \& Powell, 2003). Furthermore, SMEs would also have greater tendency to deploy ebusiness applications to enhance their core business functions rather than other supporting activities (Bharati \& Chaudhury, 2009). This clearly suggests the importance of aligning various e-business capabilities to the most crucial aspects of the SMEs operation. Appropriate e-business alignment is getting more critical considering firms allocated limited resources to invest in ebusiness. 
Although many studies have investigated Internet diffusion across business processes, there are still scarce studies on aligning ebusiness applications/solutions to the most crucial functions of a firm business processes. This study therefore bridges the gap by assessing the current state of ebusiness alignment across differing complexity of business processes. The next section discusses the concept of fit and its application in IT/IS domain.

\section{Concept of Fit and E-business Alignment}

Concept of fit as proposed by Burns and Stalker (1961) anchors the main hypothesis of contingency theory. The theory surmises that (1) 'there is no best way to organize; and (2) any way of organizing is not effective' (Galbraith, 1973, p.2). Most importantly, the theory contends that the fit between business structure and contingency factors leads to better firm performance (Venkatraman, 1989). The concept of fit and contingency theory has initially received considerable attention in understanding organizational behavior (Donaldson, 2001).

Nevertheless, due to the emerging role of IT/IS in business operation, there has been a growing concern on how firms could maximize values from the IT/IS investment. Therefore, extending the concept of fit, Henderson and Venkatraman (1993) propose a Strategic Alignment Model (SAM) as a framework to understand fit/alignment from IT/IS perspective. The model conceptualizes alignment as a multidimensional construct with four major domains; namely; business strategy, IT strategy, organizational infrastructure and IT infrastructure. SAM indicates alignment to take place either at strategic level or at operational level (Cragg et al, 2007). Strategic alignment involves synchronization

between firm's IT strategy and business strategy. Meanwhile, operational level alignment primarily focuses on aligning IT infrastructure and processes with firm infrastructure and processes.

Chan et al (1997) are among the first to provide empirical evidences based on the SAM model and to confirm the moderating effect of strategic alignment to IS performance and firm performance. Since then, other similar works follow suit (Bergeron et al, 2001; Chan et al, 2006). Nevertheless, to date, studies mainly concentrate on strategic level alignment (Chan et al, 2006; Sabherwal \& Chan, 2001), while there are limited attempts to investigate operational level alignment (Cragg et al, 2007). This is a crucial considering the fact that implementation of firms strategies requires an effective interaction of interrelated business activities (Tallon, 2007).

On another respect, most of the studies primarily investigate IT/IS alignment among large entities (Chan et al, 2006; Sabherwal \& Chan, 2001). Meanwhile, works to understand alignment in SMEs context are relatively scarce. Hussin et al (2002) are among the earlier researchers to investigate IT/IS alignment within the SMEs setting. They reported that IT/IS alignment issue does matter and therefore deserves further investigation. Cragg et al (2002) further ascertained the positive relationship between IT/IS alignment and firm performance. From an accounting information systems perspective, Ismail and King $(2007 ; 2005)$ also reported the lack of fit between accounting information requirements and accounting information systems capabilities among Malaysian SMEs. More recently, Cragg et al (2007) have found that IT/IS seems to provide inconsistent support across various business functions. Their work further indicates the need to investigate IT/IS alignment at business process level.

\section{Research Model}

Fig. 1 illustrates the proposed research model for the present study. To address the 
research gap, this study first explores relative importance of various business processes to firms (business process importance) and the extent to which ebusiness is deployed to support the business processes (e-business capabilities). Most importantly, this paper further explores the fit between 'business process importance' and 'e-business capabilities' (e-business alignment). As such, e-business alignment is a derived construct resulting from an interaction of the two other constructs. As the research model further depicts, the next attempt is to figure out several profiles with distinct characteristics of e-business alignment.

The research framework is based upon Strategic Alignment Model advocated by
Henderson and Venkatraman (1993). As indicated earlier, the model refers to operational (process) alignment as the fit between firm infrastructure and processes with IT infrastructure and processes. Considering specific IT/IS domain, this paper therefore investigates alignment between 'business process importance' and 'ebusiness capabilities'. This conceptualization is consistent with Van de Ven and Drazin's (1985) contention on applicability of fit/alignment concept beyond structural contingency perspective. They noted that the concept of fit applies as long as the theory proposes that performance is a function of match, congruence, intersection or union of two or more variables.

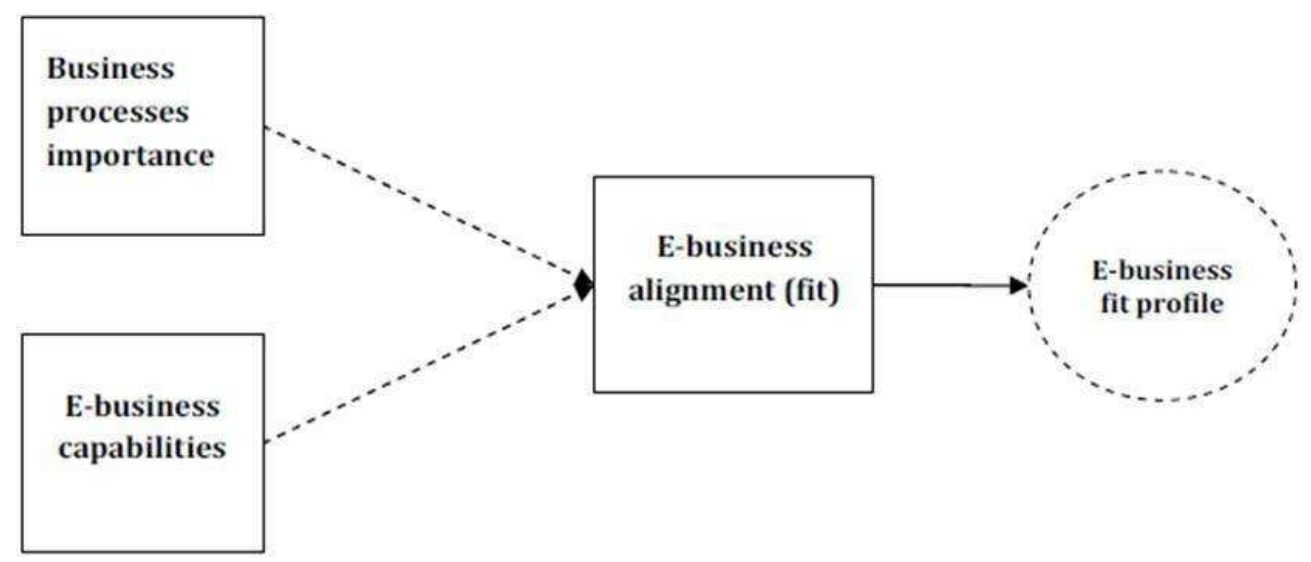

Fig1. Research Model

\section{Methodology}

\section{Survey Design and Sample}

Considering the varying definitions of SMEs, this study defines SMEs according to the National SMEs Development Council (2005) guideline. The guideline specifies small firm to be with full time employees (FTEs) of between 5 and 50 (manufacturing-based) or between 5 and 20 (service-based).
Meanwhile, a medium firm category encompasses firms with FTEs between 50 and 150 (manufacturing-based) or between 20 and 50 (service-based). However, authors exclude micro firms (less than five FTEs) considering their limited e-business capabilities and the unique nature of their operation (Schubert \& Leimstoll, 2007). In addition, samples of the present study comprise of Malaysian SMEs that are having website, as it is somehow well-accepted indicator for firms practicing e-business (Brand \& Huizingh, 2008). 
Data collection involves distribution of a selfadministered questionnaire to 1,600 firms selected from two company directories i.e. SME Corporation and Malaysia External Trade Development Corporation (MATRADE). The targeted respondent is the owner/manager of the firm who is expected to have sufficient knowledge about the firm operation and the nature of e-business practices. Besides, getting responses from those with direct responsibility for a firm ITrelated matters could be difficult as most SMEs hardly have a formal IT/IS unit (Bharati \& Chaudhury, 2009).

After about three months, 155 firms responded to the survey but only 140 responses (9\% response rate) are usable for analysis. Due to the relatively low response rate, a non-response bias test has been carried out using time-trend extrapolation approach (Armstrong and Overton, 1977). The samples were divided into two groups based on the median response date. The Mann-Whitney U-test does not indicate any substantial differences between the groups with respect to several demographic factors, i.e. nature of operation, size of firms and present Internet usage. This suggests that the presence of non-response bias is relatively minimal.

\section{Concepts and Measures}

\section{Business Processes}

To start with, business processes that are potentially supported by the Internet have been compiled from extensive literature review. The activities included are generic in nature to represent firms in various business sectors. Consequently, this study does not consider functions that are specific to certain sectors such as production-related tasks. Based upon several works, 39 activities are shortlisted (Lefebvre et al, 2005; Magal \& Kosalge, 2006; Wilson et al, 2008). These activities are initially classified into three categories: internal operation, procurement and sales-related (Levy et al, 2005). Twentyfive (25) e-business academic experts and
SMEs representatives have evaluated these items to ensure their validity, clarity and appropriateness. Based on the feedback received, a final instrument retained 36 items with slight modification on the wordings. These refined items then formed a basis for assessing the 'business process importance' and 'e-business capabilities' that correspond to each business process.

Following Cragg et al (2007) approach, this study operationalizes 'business process importance' to be perceived as the strategic importance of each of the business processes. Meanwhile, consistent with the study objective of understanding e-business deployment across firm functions, authors operationalize 'e-business capabilities' as perceived level of Internet-technology support to the respective business process. This approach relies heavily upon Chan et al (1997) work. Nevertheless, as Chan et al (1997) examined the alignment of IT capabilities with Venkatraman's (1989) business strategy construct, this study assesses the alignment of 'e-business capabilities' against 'business process importance'. From e-business environment perspective, the approach is also consistent with Raymond and Bergeron (2008), whom operationalize 'e-business capabilities' as the extent of support that Internet technologies currently provide to each of the business functions identified.

Consistent with earlier works (Chan et al, 1997; Hussin et al, 2002; Ismail and King, 2007), this study employs a bi-variate alignment approach in order to capture information about 'business process importance' and 'e-business capabilities'. Using this approach, a set of questions was designed to measure firm perception on relative strategic importance of each of the 36 business processes. Meanwhile, authors posed another set of questions to assess the extent of Internet technology supports to the respective business process. Thus, responses for two sets of questions were obtained with 72 questions in total (36 questions on 'business process importance' and the 
corresponding 36 questions on 'e-business capabilities').

With respect to measurement scale, a 'business process importance' construct is measured using a five-point scale with ' 1 ' indicating 'not important at all' and ' 5 ' as 'highly important'. Consistently, a five-point scale is also considered for measuring 'ebusiness capabilities' with ' 1 ' representing 'not supported at all' and ' 5 ' indicating 'highly supported'. Ratings obtained for both constructs then form a basis to determine ebusiness alignment.

\section{E-business Alignment (Fit)}

There have been constant debates on measuring fit as it corresponds to different mathematical computation and analysis technique (Van de Ven \& Drazin, 1985). Venkatraman (1989) suggested six (6) perspectives of fit: moderation, mediation, matching, co-variation, profile deviation and gestalt. Nevertheless, moderation and matching perspectives have been widely considered in previous works (Chan et al, 1997; Premkumar et al, 2005). Some other studies further noted that moderation approach seems to be more meaningful especially in associating alignment to firm performance (Cragg et al, 2002; Ismail \& King, 2005). The moderation approach measures fit as an interaction effect between two variables and subsequently assesses its effect to firm performance. At the same time, moderation approach provides greater merit (by producing higher score) when high alignment occurs at the most crucial functions rather than high alignment which takes place at least crucial functions (Hooper et al, 2010).

Chan et al (1997) however caution of 'antisynergy' effect resulting from moderation approach. 'Anti-synergy' refers to the situation in which firms with very different scores of 'business process importance' and 'e-business capabilities' (indicating a different level of alignment) are assigned with the same e-business fit scores. In response, Hooper et al (2010) refines the measurement approach by retaining the advantages of both matching and moderation approach while minimizing the 'anti-synergy' problem. Consequently, this study employs the refined measurement approach to determine e-business fit score using the following formula, which assumes values ranging from 0 (very low fit) to 20 (very high fit).

E-business fit score $=(4-|x-y|) *((x+y)$ (2)

Where $x$ refers to the rating of 'business process importance' and y refers to rating of 'e-business capabilities' of a particular process.

\section{Findings}

Table 1 reports distribution of samples on several demographic factors. As the table indicates, manufacturing-based firms dominate around 70 percent of the samples. Meanwhile, there is relatively equal representation between small and mediumsized firms. As for market orientation, about two-thirds of the responding firms are involved in export activities, while the remaining firms merely serve domestic market. Lastly, the analysis further shows that the responding firms have diverse ebusiness experience. About 10 percent merely use e-mail, while about 40 percent are presently at web presence stage and prospecting stage. Meanwhile, less than 15 percent the firms have reached higher ebusiness ladders (integration and transformation).

With respect to respondent position, more than 90 percent of the respondents are serving managerial positions. Specifically, almost 50 percent of the respondents are presently holding top management positions in the firms (owner/CEO). With respect to working experience, about 58 percent of the respondents have been working with the firm for more than five years. These facts lay greater weight on respondents' credibility. 
Finally, in terms of gender, male are more dominant than female respondents. To check for possible response bias, a Mann-Whitney U-test was executed to assess responses consistency across selected firms demographic information and respondents' profiles. The results clearly indicate minimal differences of responses on major research variables.

\section{E-business Capabilities and Assessment of Alignment}

Preliminary analysis reveals that Internet support is somewhat extensive for information searching, communication and marketing-related tasks that is consistent with other similar studies in Malaysia (Alam et al, 2007; Hussin et al, 2008; Tan et al, 2011). This is because these are among the functions that are easily transformed by the Internet (Koh \& Nam, 2005). Meanwhile, transactional-related activities, such as payment, order processing and documents exchanges are not widely available in most firms. This is due to such capabilities require more sophisticated and expensive IT infrastructure (Tagliavini et al, 2001). Thus, not many firms can afford integrating the Internet to support these processes. The result also suggests that Malaysian firms are now reaching a prospecting stage. At the prospecting stage, despite the fact that internet usage relatively goes beyond e-mail usage or basic web presence, the uses of applications that transform transactionalrelated activities are still limited (Cheong et al, 2009).

E-business fit score represents the extent of e-business alignment of a particular business process. Overall results show that the levels of e-business alignment are not consistent across various business functions. Activities related to information searching, advertising and customer service are relatively having better alignment than other activities. On the other hand, results indicate lower alignment for activities such as payment-related activities, employees training and contract negotiation (Appendix 1). 
Table 1: Demographic Information of Responding Firms

\begin{tabular}{|l|c|c|l|c|c|}
\hline Age of firm & $\mathbf{n}$ & $\mathbf{\%}$ & Position & $\mathbf{n}$ & $\mathbf{\%}$ \\
\hline Less than 10 years & 42 & 30.6 & Owner/proprietor & 38 & 27.1 \\
\hline 10 - 20 years & 49 & 35.8 & CEO & 28 & 20.0 \\
\hline 20 - 30 years & 24 & 17.5 & Senior Manager & 40 & 28.6 \\
\hline 30 years and above & 22 & 16.1 & Manager & 22 & 15.7 \\
\hline Not disclosed & 3 & & Others & 12 & 8.6 \\
\hline Sector & & & Gender & & \\
\hline Manufacturing -based & 94 & 67.1 & Male & 98 & 70.0 \\
\hline Non-manufacturing based & 46 & 32.9 & Female & 42 & 30.0 \\
\hline Firm Size & & & Length of & & \\
\hline Small & 73 & 52.1 & Less than 5 years & 58 & 42.0 \\
\hline Medium & 67 & 47.9 & $5-10$ years & 35 & 25.4 \\
\hline Market orientation & & & 11 - 15 years & 22 & 15.9 \\
\hline Domestic market only & 42 & 30.2 & More than 15 years & 23 & 16.7 \\
\hline Domestic and less than 50\% export market & 65 & 46.8 & Not disclosed & 2 & \\
\hline Domestic and more than 50\% export market & 32 & 23.0 & & & \\
\hline Not disclosed & 1 & & & & \\
\hline Current stage of Internet usage & & & & & \\
\hline Level 0 - Email & 11 & 7.8 & & & \\
\hline Level 1 - Web presence & 54 & 38.6 & & & \\
\hline Level 2 - Prospecting & 55 & 39.3 & & & \\
\hline Level 3 - Business integration & 14 & 10.0 & & & \\
\hline Level 4 - Business transformation & 6 & 4.3 & & & \\
\hline$n=140$ & & & & \\
\hline
\end{tabular}

However, assessment of alignment on individual business process provides limited understanding of the situation taking in consideration that some business activities are potentially related. Hence, computation of aggregate e-business fit score could be useful to facilitate further analysis. For this purpose, a Principal component analysis (PCA) was first employed to reveal higher order dimensions that might represent both 'business process importance' and 'ebusiness capabilities'. The PCA is useful to unleash meaningful structure from the sample data (Tabachnick \& Fidell, 2007). Initial checks on both constructs provide strong support on factorability of the data. This is based on Kaiser-Meyer-Olkin (KMO) values for both 'business process importance' and 'e-business capabilities' of 0.915 and 0.874 respectively. Similarly, the Bartlett tests of sphericity values are also significant for both constructs.

A Varimax rotation procedure employed however did not produce any meaningful structure for both constructs with several cross-loading items. Consistent with Hair et al (2010), this study therefore considers an oblique rotation procedure to refine the PCA results for easier interpretation. The PCA results suggest a refined framework with 32 items in five dimensions. The components can be appropriately labelled as 'sales and after sales', 'procurement-related', 'accounting and financial-related', 'information searching' and 'in-house 
operation' (finalized items retained for each process dimension is presented in Appendix 2).

E-business fit score for each process dimension is determined by obtaining the average fit scores of all items representing the respective process dimension. Table $\mathbf{2}$ presents mean product of 'business process importance', 'e-business capabilities' and 'ebusiness fit score' across process dimensions. Overall, the results indicate the presence of e-business alignment/misalignment within the SMEs context. Specifically, firms perceive the Internet to be closely aligned with information searching, sales-related functions and in-house operation. Meanwhile, lower alignments are noticeable for financial-related and procurement functions. Consistent with earlier works (Cragg et al, 2007; Tallon, 2007), these results suggest diversity of e-business alignment across business functions. As indicated further, firms have greater tendencies to integrate e-business applications to support most salient functions of their firms while substantially minimizing e-business investment in least salient functions. The next section proceeds to classify the sample firms based on their ebusiness fit characteristics.

Table 2: Mean Scores by Business Process Dimensions

\begin{tabular}{|l|c|c|c|}
\hline Dimensions (no. of items) & $\begin{array}{c}\text { Business process } \\
\text { importance }\end{array}$ & $\begin{array}{c}\text { E-business } \\
\text { capabilities }\end{array}$ & $\begin{array}{c}\text { E-business fit } \\
\text { score }\end{array}$ \\
\hline Procurement related (8) & 3.38 & 2.68 & 9.37 \\
\hline Sales and after sales service (13) & 3.79 & 3.12 & 11.16 \\
\hline Accounting and financial (3) & 3.11 & 2.40 & 8.67 \\
\hline In-house operation (4) & 3.54 & 3.02 & 10.95 \\
\hline Information searching (4) & 4.08 & 3.56 & 12.89 \\
\hline
\end{tabular}

\section{E-business Fit Profiles}

Considering inconsistencies of e-business alignment patterns across business functions, it is interesting to further investigate for the existence of any possible patterns with respect to e-business fit characteristics across firms. Hence, this study has considered cluster analysis due to its capability to classify objects such as respondents, products or other entities based on given characteristics (Hair et al, 2010). The clustering procedure is executed using hierarchical clustering approach (Ward method) with fit scores of all process dimensions as the clustering variables. Meanwhile, an agglomeration coefficient change becomes a basis to determine the most optimal cluster solution. Clustering result (Table 3) indicates a two-cluster solution could be appropriate to represent the samples based on the highest change in coefficient value $(48.6 \%)$. However, in most cases the two-cluster solution always produces the highest coefficient change and thus might not adequately represent profiles of the samples unless being supported by strong theoretical justification (Hair et al, 2010). Consequently, the next solution with highest coefficient change could be selected, i.e. three-cluster solution (22.9\%). In other words, the cluster analysis suggests three distinct groups of firms with different ebusiness fit characteristics. 
Table 3: Partial Extract of Cluster Analysis Output

\begin{tabular}{|c|c|c|c|}
\hline $\begin{array}{c}\text { Number of clusters } \\
\text { after combining }\end{array}$ & $\begin{array}{c}\text { Agglomeration } \\
\text { coefficient }\end{array}$ & Change in coefficient & $\begin{array}{c}\text { Proportionate increase in } \\
\text { coefficient to next stage (\%) }\end{array}$ \\
\hline 5 & 4248.12 & 415.21 & 9.77 \\
\hline 4 & 4663.33 & 441.64 & 9.47 \\
\hline $\mathbf{3}$ & $\mathbf{5 1 0 4 . 9 7}$ & $\mathbf{1 1 7 1 . 9 7}$ & $\mathbf{2 2 . 9 6}$ \\
\hline 2 & 6276.94 & 3055.69 & 48.68 \\
\hline 1 & 9332.63 & - & - \\
\hline
\end{tabular}

Table 4 reports comparative fit scores among clusters. As presented in the table, slightly lower than 50 percent of the samples (62 firms), fit into the second cluster while the first and the third clusters have 35 and 43 memberships respectively. For validation purpose, one-way ANOVA indicates significant mean differences across three clusters with respect to all clustering variables. The post-hoc tests (not disclosed) also indicate significant differences between clusters. Both tests suggest that all three clusters have relatively heterogeneous ebusiness fit characteristics. Thus, the clustering result is rather reliable and valid.

Table 4: Comparative Characteristics of E-business Fit by Clusters

\begin{tabular}{|l|c|c|c|c|c|}
\hline & \multicolumn{3}{|c|}{ E-business fit score (mean) } & ANOVA \\
\hline Process dimensions & $\begin{array}{c}\text { Cluster 1 } \\
(\mathbf{n = 3 5 )}\end{array}$ & $\begin{array}{c}\text { Cluster 2 } \\
(\mathbf{n = 6 2 )}\end{array}$ & $\begin{array}{c}\text { Cluster 3 } \\
(\mathbf{n = 4 3 )}\end{array}$ & $\begin{array}{c}\text { Overall } \\
(\mathbf{n = 1 4 0 )}\end{array}$ & F-value \\
\hline Sales and after sales & 14.17 & 11.29 & 7.26 & 11.17 & $74.94^{*}$ \\
\hline Procurement & 11.77 & 9.53 & 6.16 & 9.38 & $54.48^{*}$ \\
\hline Accounting and financial & 12.07 & 8.20 & 5.35 & 8.68 & $39.34^{*}$ \\
\hline Information searching & 16.63 & 12.22 & 9.51 & 12.90 & $63.15^{*}$ \\
\hline In-house operation & 14.65 & 10.99 & 6.37 & 10.96 & $58.73^{*}$ \\
\hline
\end{tabular}

*Significant at $95 \%$ confidence level

Fig. 2 below further illustrates the comparison using graphical representation. The diagram denotes two important aspects of alignment characteristics across clusters. First, a horizontal comparison indicates that e-business fit scores are relatively higher for information searching, in-house operation and sales-related functions. Obviously, the pattern seems to be highly consistent across clusters. Secondly, a vertical comparison shows that firms in the first cluster have comparatively higher fit scores in all business processes compared to other clusters. Meanwhile, firms in the third cluster report consistently low level of alignment for all aspects of operation. These observations suggest that the most obvious differing characteristic amongst clusters is their overall e-business fit score (vertical comparison) instead of perceived alignment at different business process dimensions (horizontal comparison). The cluster classification results are consistent with earlier studies of IT/IS alignment (Ismail \& King, 2007; Cragg et al, 2002). 


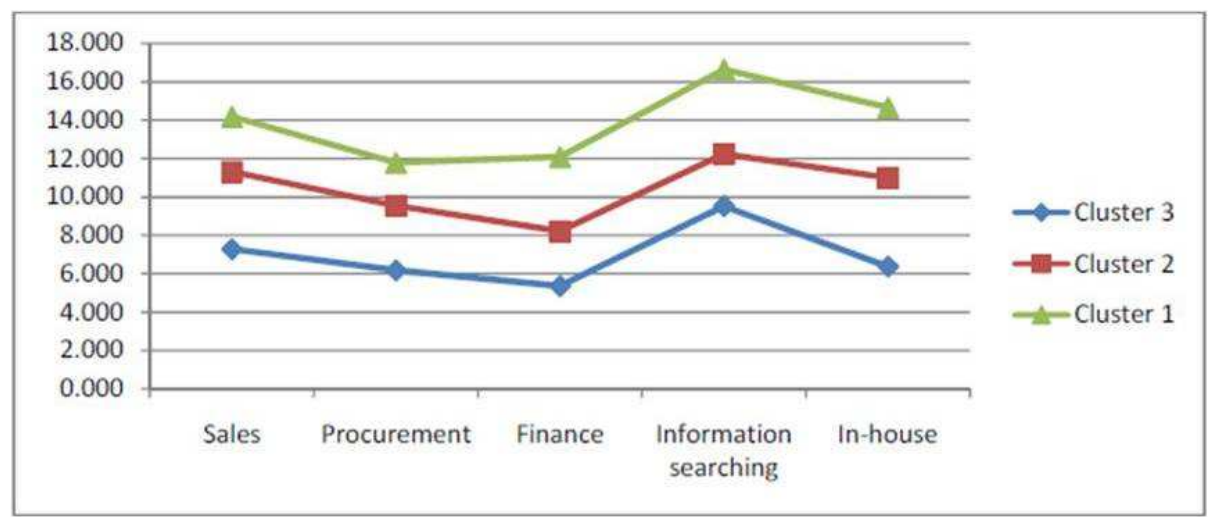

Fig2. Comparative E-Business Fit Characteristics across Clusters (Mean Score)

Fig. 3 further shows comparison of ebusiness fit characteristics based on meancentered value (the differences between a cluster mean score and overall mean score). As the figure indicates, the first cluster has greater than average fit scores for all aspects of processes. In contrast, fit scores for firms classified into the third cluster are substantially lower than average especially for sales and in-house operation. Finally, fit scores for the second cluster are slightly above overall mean scores except for finance and information searching functions.

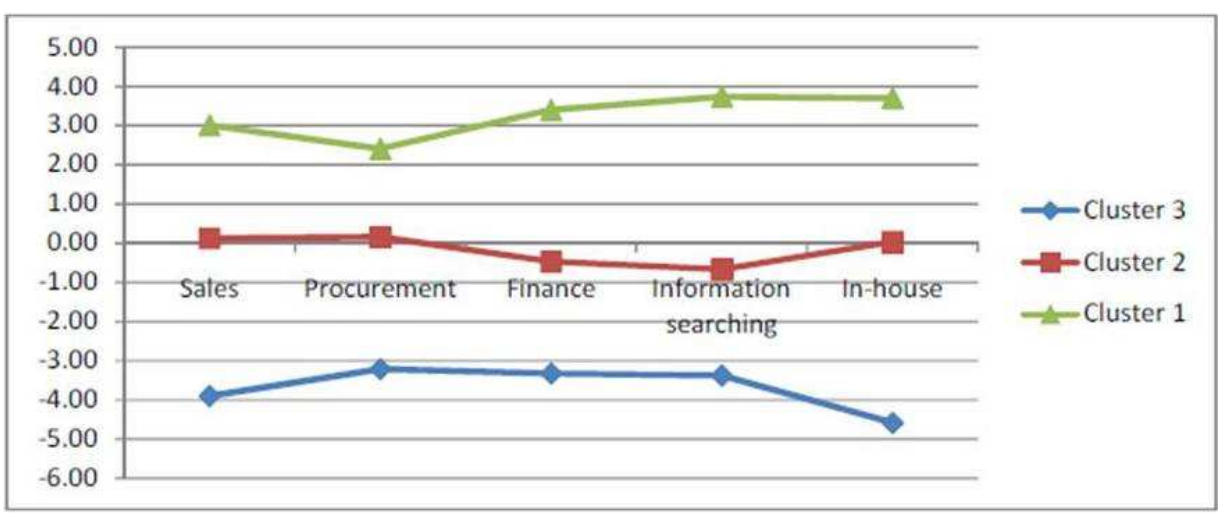

Fig3. Comparative E-business Fit Characteristics across Clusters (Mean-Centered Value)

The pattern revealed in Fig. 2 and Fig. 3 then would be a basis for naming the clusters. Based on the above analysis, it is appropriate to propose that the first cluster represents firms with relatively higher e-business fit score in all business functions. Therefore, the cluster could be labelled as 'highly fit'. Meanwhile, as the second cluster comprises firms with comparatively moderate fit score in almost all aspects, it is thus acceptable to label this group as 'moderately fit'. Finally, the third cluster comprises firms with relatively lowest fit score for all functions and therefore suits the label of 'low fit'.

With respect to e-business alignment characteristics, firms in the 'highly fit' cluster perceive greater importance of e-business applications and those applications have been deployed to support the most crucial functions of the firms. In other words, Internet capabilities of these firms are closely aligned to the most essential aspects of the firm functions. In contrast, although firms 
classified under 'low fit' category do find several functions are crucial to their business, they perceive limited e-business potentials to enhance efficiency of those business functions. Thus, it is presumed that firms hardly find strategic e-business values to facilitate their business operation. Finally, about two-thirds of the responding firms classified under 'moderately fit' category are in the transformation stage as they keep exploring Internet potentials to support their business.

\section{Discussion and Conclusions}

E-business offers wide range of supports to extend firm's productivities. Nevertheless, SMEs are relatively more prudent concerning e-business-related investment due to resources constraint. Hence, they would have to focus their investment particularly to enhance the most crucial functions of the firms in order to manage e-business effectively. This paper, therefore explores current state of e-business alignment across various business functions. Preliminary analysis of 'business process importance' shows that firms perceive certain business functions as more important than other functions. In terms of e-business capabilities, the degree of e-business support is relatively lower even for most crucial functions of the firms. This pattern suggests that there are still wide opportunities for firms to improve their e-business capabilities.

Considering both aspects of 'business process importance' and 'e-business capabilities', the next step was to investigate as to what extent that the e-business capabilities employed correspond to the most strategic functions of the firms. The results show that higher alignment is more noticeable on sales, information searching and in-house functions. Meanwhile, firms perceive relatively lower level of alignment with respect to procurement and accounting/financial functions.

Cluster analysis further proposes three profiles with distinct e-business fit characteristics. The clusters were named as 'highly fit', 'moderately fit' (transforming) and 'low fit' (limited potential). The results also reveal that majority of the firms reside in the second cluster while relatively lower proportion of the firms that successfully reach higher level of alignment. This could be another justification for slow progress of ebusiness deployment amongst SMEs. The result suggests that e-business does not equally fit all SMEs in the same manner. Although large proportion of the SMEs has initiated e-business use, many do not progress further to more advanced stages. This is disappointing since remaining at an early stage of e-business ladder restricts firms from optimizing real values of $e$ business (Magal et al, 2009).

These findings benefit e-business and SMEs researchers by providing another perspective of investigating e-business phenomenon. The study views the problem from a fit perspective and thus provides a different insight with a view to have better understanding of e-business practices amongst SMEs. The outcome would also benefit SMEs-related agencies to customize their strategies in promoting e-business to the SMEs. A more focused approach, i.e. by identifying and providing necessary support for most potential firms to progress in ebusiness, is more useful than employing a blanket approach to all SMEs at large.

Readers should take into account several limitations in generalizing these findings. First, the sample size is relatively small, though this is a commonplace for studies involving owner/manager of SMEs (Dennis, 2003). Having obtained larger responses would enhance representation of the SMEs population at large. Secondly, the survey has been conducted among SMEs in developing country. Further validation can be useful by comparing the results with other developing or developed nations.

Future works could further ascertain any linkage between different characteristics of fit and performance impact. In case there is a positive impact of e-business fit on performance, it could be a good sign for firms 
to put continuous effort in aligning their ebusiness capabilities. In addition, future works could also investigate discriminating factors among firms with different fit profiles. This is obviously crucial to provide reasons for why some firms have better ebusiness alignment than other firms.

\section{Acknowledgment}

Authors would like to thank the Ministry of Higher Education Malaysia and Universiti Utara Malaysia for funding this research project via Fundamental Research Grant Scheme (FRGS).

We would also like to thank participants of $16^{\text {th }}$ IBIMA conference for their fruitful comments to improve this paper. The conference was held in Kuala Lumpur on 29 30 June 2011.

\section{References}

Alam, S .S., Khatibi, A., Ahmad, M. I. S. \& Ismail, H. B. (2007). "Factors Affecting ECommerce Adoption in the Electronic Manufacturing Companies in Malaysia," International Journal of Commerce and Management, 17(1/2), pp. 125 - 139.

Aragon-Correa, J. A. \& Cordon-Pozo, E. (2005). "The Influence of Strategic Dimensions and the Environment on the Introduction of Internet as Innovation into Small and Medium-Sized Enterprises," Technology Analysis \& Strategic Management, 17(2), p. 205-218.

Armstrong, J. S. \& Overton, T. S. (1977). "Estimating Non-Response Bias in Mail Surveys," Journal of Marketing Research, 14, pp. 396-402.

Bergeron, F., Raymond, L. \& Rivard, S. (2001). "Fit in Strategic Information Technology Management Research: An Empirical Comparison of Perspectives," Omega, 29(2), pp. 125-42.

Bharadwaj, P. N. \& Soni, R. G. (2007). "Ecommerce Usage and Perception of E-
Commerce Issues among Small Firms: Results and Implications from an Empirical Study," Journal of Small Business Management, 45(4), 501 - 521.

Bharati, P. \& Chaudhury, A. (2006). "Studying the Current Status of Technology Adoption," Communications of the ACM, 49(10), 88 - 93.

Bharati, P. \& Chaudhury, A. (2009). 'SMEs and Competitiveness: The Role of Information Systems,' International Journal of E-Business Research, 5(1), i -ix.

Brand, M. J. \& Huizingh, E. K. (2008). "Into the Drivers of Innovation Adoption: What Is the Impact of the Current Level of Adoption?," European Journal of Innovation Management, 11(1), 5 - 24.

Burns, T. \& Stalker, G. M. (1961). 'The Management of Innovation,' Oxford University Press, New York, USA.

Chan, Y. E., Huff, S. L., Barclay, D. W. \& Copeland, D. G. (1997). "Business Strategic Orientation, Information Systems Strategic Orientation, and Strategic Alignment," Information Systems Research, 8(2), 125 150.

Chan, Y. E. \& Reich, B. H. (2007). "State of the Art IT Alignment: What Have We Learned?," Journal of Information Technology, 22, p.297315.

Chan, Y. E., Sabherwal, R. \& Tatcher, J. B. (2006). "Antecedents and Outcomes of Strategic IS Alignment: An Empirical Investigation," IEEE Transactions on Engineering Management, 53(1), 27-47.

Cheong, T. Y., Sulaiman, A. \& Parveen, F. (2009). "Internet Adoption among Malaysian Companies," Journal of Asia-Pacific Business, 10(2), 165 - 185.

Cragg, P., King, M. \& Hussin, H. (2002). "IT Alignment and Firm Performance in Small Manufacturing Firms," Journal of Strategic Information Systems, 11, p. 109-132. 
Cragg, P., Tagliavini, M. \& Mills, A. (2007). "Evaluating the Alignment of IT With Business Processes in SMEs," Proceeding of the 18th Australasian Conference on Information Systems, 5 - 7 December 2007, Toowoomba, Australia.

Cragg, P. B. \& Zinatelli, N. (1995). "The Evolution of Information Systems in Small Firms," Information \& Management, 29, 1-8.

DeLone, W. H. (1988). "Determinants of Success for Computer Usage in Small Business," MIS Quarterly, 12(1), 51 - 61.

Dennis, W. J. (2003). "Raising Response Rates in Mail Surveys of Small Business Owners: Results of an Experiment," Journal of Small Business Management, 41(3), 278 - 295.

Donaldson, L. (2001). 'The Contingency Theory of Organization,' Sage Publication, California, USA.

Galbraith, J. R. (1973). 'Designing Complex Organization,' Reading, MA: Addison-Wesley Publishing Co.

Gibbs, J. L. \& Kraemer, K. L. (2004). "A CrossCountry Investigation of the Determinants of Scope of E-Commerce Use: An Institutional Approach," Electronic Markets, 14(2), 124 137.

Hair, J. F., Black, W. C., Babin, B. J. \& Anderson, R. E. (2010). "Multivariate Data Analysis," Pearson Prentice Hall, New Jersey, USA.

Hashim, N. A. (2009). "E-Commerce and SMEs - The Need for Caution," Prometheus, $27(2), \quad 125-40$.

Henderson, J. C. \& Venkatraman, H. (1993). "Strategic Alignment: Leveraging Information Technology for Transforming Organizations," IBM Systems Journal, 32(1), 4 - 16.

Hooper, V. A., Huff, S. L. \& Thirkell, P. C. (2010). "The Impact of Is-Marketing Alignment on Marketing Performance and Business Performance," The Database for
Advances in Information Systems, 41(1), 36 55.

Hussin, H., Noor, R. M. \& Suhaimi, M. A. (2008). "Perceived Attributes of E-Commerce and the Adoption Decision: The Case of Malaysian SMEs," Journal Teknologi Maklumat \& Multimedia, 5, 107-25.

Hussin, H., King, M. \& Cragg, P. (2002). "IT Alignment in Small Firms ," European Journal of Information Systems,11(2), 108 - 127.

Ismail, N. A. \& King, M. (2005). "Firm Performance and AIS Alignment in Malaysian SMEs," International Journal of Accounting Information Systems, 6, 241 - 259.

Ismail, N. A. \& King, M. (2007). "Factors Influencing the Alignment of Accounting Information Systems in Small and Medium Sized Malaysian Manufacturing Firms," Journal of Information Systems and Small Business, 1(1 - 2), 1 - 20.

Koh, C. E. \& Nam, K. T. (2005). "Business Use of the Internet: A Longitudinal Study from a Value Chain Perspective," Industrial Management \& Data Systems, 105(1), 82 -95.

Koh, C. E., Nam, T. K., Prybutok, V. R. \& Lee, S. (2007). "A Value Chain Perspectives of

Internet Practices, E-Readiness, and Organizational Performance: A Comparison of US and South Korean Firms," Industrial Management \& Data Systems, 107(4), 519 536.

Lefebvre, L.-A., Lefebvre, E. Elia, E. \& Boeck, H. (2005). "Exploring B-to-B E-Commerce Adoption Trajectories in Manufacturing SMEs," Technovation, 25, 1443 - 1456.

Levy, M. \& Powell, P. (2000). "Information Systems Strategy for Small and Medium Sized Enterprise: An Organizational Perspective," Journal of Strategic Information Systems, 6, $63-84$.

Levy, M. \& Powell, P. (2003). “Exploring SMEs Internet Adoption: Towards a Contingent Model," Electronic Markets, 13(2), b173-81. 
Levy, M., Powell, P. \& Worral, L. (2005). "Strategic Intent and E-Business in SMEs: Enablers and Inhibitors," Information Resources Management Journal, 18(4), 1 20.

Magal, S. \& Koslage, P. (2006). “A Classification of E-Business Applications: Preliminary Results," Proceeding of the Twelfth Americas Conference on Information Systems, 4 -6 August, Acapulco, Mexico.

Magal, S. R., Koslage, P. \& Levenburg, N. M. (2009). "Using Importance Performance Analysis to Understand and Guide E-Business Decision Making in SMEs," Journal of Enterprise Information Management, 22(1/2), 137 - 151.

Meckel, M., Walters, D., Greenwood, A. \& Baugh, P. (2004). "A Taxonomy of E-Business Adoption and Strategies in Small and Medium Sized Enterprises," Strategic Change, 13(5), $259-269$.

Melville, N. \& Ramirez, R. (2008). "Information Technology Innovation Diffusion: An Information Requirements Paradigm," Information Systems Journal, 18(3), 247-273.

Mohamad, R. \& Ismail, N. A. (2009). 'Electronic Commerce Adoption in SMEs: The Trend of Prior Studies,' Journal of Internet Banking and Commerce, 4(1), 1 - 14.

National SMEs Development Council (2005). "Definitions for Small and Medium Enterprises in Malaysia," National SMEs Development Council National SME Development Council, Kuala Lumpur, Malaysia.

Parker, C. \& Castleman, T. (2007). "New Directions for Research on SME-Ebusiness: Insights from an Analysis of Journal Articles from 2003 to 2006," Journal of Information Systems and Small Business, 1(1/2), 21 - 40.

Pflugheoft, K. A., Ramamurthy, K., Soofi, E. S., Yasai-Ardekani, M. \& Zahedi, F.M. (2003). "Multiple Conceptualizations of Small
Business Web Use and Benefit," Decision Sciences, 34(3), 467-512.

Porter, M. E. (2001). "Strategy and the Internet," Harvard Business Review, 79(3), 62 - 78.

Premkumar, G. (2003). "A Meta-Analysis of Research on Information Technology Implementation in Small Business," Journal of Organizational Computing and Electronic Commerce, 13(2), 91 - 121.

Premkumar, G., Ramamurthy, K. \& Saunders, C. S. (2005). 'Information Processing View of Organizations: An Exploratory Examination of Fit in the Context of Inter-Organizational Relationships,' Journal of Management Information Systems, 22(1), 257 - 294.

Raymond, L. \& Bergeron, F. (2008). "Enabling the Business Strategy of SMEs through EBusiness Capabilities: A Strategic Alignment Perspective," Industrial Management \& Data Systems, 108(5), 577 - 595.

Raymond, L., Bergeron, F. \& Blili, S. (2005). The Assimilation of E-Business in Manufacturing SMEs - Determinants and Effects on Growth and Internationalization, Electronic Markets, 15(2), $106-118$.

Roberts, B. \& Toleman, M. (2007). "One-Size E-Business Adoption Model Does Not Fit All," Journal of Theoretical and Applied Electronic Commerce Research, 2(3), 49 - 61.

Sabherwal, R. \& Chan, Y.E. (2001). "Alignment between Business and IS Strategies: A Study of Prospectors, Analyzers, and Defenders," Information Systems Research, 12(1), 11 - 33.

Schubert, P. \& Leimstoll, U. (2007). "Importance and Use of Information Technology in Small and Medium-Sized Companies," Electronic Markets, 17(1), 38 55.

Silvius, A. J. G., de Waal, B. \& Smit, J. (2009). “ Business and IT Alignment Answers and 
Remaining Questions" (online), Association for Information Systems. http://aisel.aisnet.org/pacis2009/44.

Tabachnick, B. G. \& Fidell, L. S. (2007). "Using Multivariate Statistics," Pearson, Boston, USA.

Tagliavini, M., Ravarini, A. \& Antonelli, A. (2001). "An Evaluation Model for Electronic Commerce Activities within SMEs," Information Technology \& Management, 2(2), $211-230$.

Tallon, P.P. (2007). “A Process-Oriented Perspective on the Alignment of Information Technology and Business Strategy," Journal of Management Information Systems, 24(3), 227-268.

Tan, K. S., Eze, U. C. \& Chong, S. C. (2011). "Effects Of Industry Type on ICT Adoption among Malaysian SMEs," Journal of Supply Chain and Customer Relationship Management, 2011(2011), 1 - 13.

Thong, J. Y. L. (2001). "Resource Constraints and Information Systems Implementation in Singaporean Small Businesses," Omega, 29(2), 143-56.
Thong, J. Y. L., Yap, C. S. \& Raman, K. S. (1996). "Top Management Support, External Expertise, and Information Systems Implementation in Small Businesses," Information Systems Research, 7(2), 248267.

Van de Ven, A. H. \& Drazin, R. (1985). "The Concept of Fit in Contingency Theory," Research In Organizational Behavior, 7, 333 365.

Venkatraman, N. (1989). "The Concept of Fit in Strategy Research: Toward Verbal and Statistical Correspondence," Academy of Management Review, 14(3), 423 - 444.

Wilson, H., Daniel, E. \& Davies, I. A. (2008). "The Diffusion of E-Commerce in UK SMEs," Journal of Marketing Management, 24(5/6), 489 - 516.

Zhu, K. \& Kraemer, K. L. (2005). "Postadoption Variations in Usage and Value of EBusiness by Organizations: Cross-country Evidence from the Retail Industry," Information Systems Research, 16(1), 61 84. 


\section{Appendices}

\section{Appendix 1: E-business Fit by Business Process Items}

\begin{tabular}{|l|l|}
\hline Business process & Fit score \\
\hline Top 10 items with the highest fit score & 13.46 \\
\hline Product information search & 12.94 \\
\hline Supplier information search & 12.24 \\
\hline Seek new customers & 12.88 \\
\hline Advertise products/services & 12.83 \\
\hline Search industry/economic information & 12.59 \\
\hline Manage customers' inquiries & 12.76 \\
\hline Firm background information & 12.33 \\
\hline Communicate product specifications & 12.36 \\
\hline Search competitors information & 12.19 \\
\hline Obtain customers feedbacks & \\
\hline & \\
\hline Top 10 items with the lowest fit score & 9.43 \\
\hline Deliver products/services & 9.45 \\
\hline Manage firm accounting/finance & 9.45 \\
\hline Track purchase delivery & 9.33 \\
\hline Track purchase order & 9.34 \\
\hline Receive product/service & 9.03 \\
\hline Allow customers to track orders & 8.64 \\
\hline Make payment to supplier & 8.83 \\
\hline Manage employees training & 8.25 \\
\hline Communicate with shareholders & 7.69 \\
\hline Firm financial result & \\
\hline Non-inventory purchase & \\
\hline & \\
\hline & \\
\hline & \\
\hline & \\
\hline & \\
\hline & \\
\hline & \\
\hline & \\
\hline & \\
\hline & \\
\hline
\end{tabular}


19 Journal of Internet and e-Business Studies

Appendix 2: Dimensions of Business Processes

\begin{tabular}{|c|}
\hline $\begin{array}{l}\text { Component 1: Sales and after sales (13 items) } \\
\text { Describe product usage information } \\
\text { Advertise products/services } \\
\text { Manage customers' inquiries } \\
\text { Seek new customers } \\
\text { Obtain customers feedbacks } \\
\text { Process customers order } \\
\text { Negotiate contract with customer } \\
\text { Communicate product specifications } \\
\text { Provide customer support services } \\
\text { Exchange sales related documents } \\
\text { Deliver products/services } \\
\text { Allow customers to track orders } \\
\text { Receive payment from customers }\end{array}$ \\
\hline $\begin{array}{l}\text { Component 2: Procurement (8 items) } \\
\text { Track purchase order } \\
\text { Track purchase delivery } \\
\text { Place purchase order } \\
\text { Make payment to supplier } \\
\text { Receive product/service } \\
\text { Contract negotiation } \\
\text { Exchange purchase information } \\
\text { Non-inventory purchase }\end{array}$ \\
\hline $\begin{array}{l}\text { Component 3: Internal operation (4 items) } \\
\text { Internal communication among employees } \\
\text { Sharing information/data among employees } \\
\text { Provide firms updates to employees } \\
\text { Coordinate new products/services development }\end{array}$ \\
\hline $\begin{array}{l}\text { Component 4: Information searching (4 items) } \\
\text { Product information search } \\
\text { Supplier information search } \\
\text { Search industry/economic information } \\
\text { Search competitors information }\end{array}$ \\
\hline $\begin{array}{l}\text { Component 5: Accounting/financial (3 items) } \\
\text { Firm financial result } \\
\text { Communicate with shareholders } \\
\text { anage firm accounting/finance }\end{array}$ \\
\hline
\end{tabular}

